\title{
Polyanionic carbosilane dendrimers as a new adjuvant in combination with latency reversal agents for HIV treatment
}

Ignacio Relaño-Rodríguez ${ }^{1,2,3,4}$, Raquel Juárez-Sánchez ${ }^{1,2,3}$, Carolina Pavicic ${ }^{4}$, Eduardo Muñoz ${ }^{5}$ and Maria Ángeles Muñoz-Fernández ${ }^{1,2,3^{*}}$ (1)

\begin{abstract}
Background: The major obstacle impeding human immunodeficiency virus-1 (HIV-1) eradication in antiretroviral treatment (ART) treated HIV-1 subjects is the establishment of long-lived latently infected resting $\mathrm{CD}^{+}{ }^{+} \mathrm{T}$ cells. Due to the fact that no drug has been effective, the search for new drugs and combinations are a priority in the HIV cure. Treatments based on nanotechnology have emerged as an innovative and promising alternative to current and conventional therapies. In this respect, nanotechnology opens up a new door for eliminating latent HIV infection. We studied the role of G1-S4, G2-S16 and G3-S16 polyanionic carbosilane dendrimers in the context of latent HIV-1 persistence. Moreover, we study the efficiency of these dendrimers in combination with latency reversal agents (LRAs) against HIV-1 infection.
\end{abstract}

Methods: J89GFP lymphocyte and THP89GFP monocyte derived cell lines latently infected with HIV-1 p89GFP were used as an in vitro model of latency for our study. Viability assays by 3-(4-5-dimethylthiazol-2-yl)-2,5-diphenyltetrazolium bromide (MTT) and lactate dehydrogenase (LDH) were performed to determine the working concentrations of dendrimers and LRAs. Both cell lines were treated with G1-S4, G2-S16 and G3-S16 either alone or in combination with bryostatin (BRY), romidepsin (RMD) or panobinostat (PNB) for 24 and $48 \mathrm{~h}$. The expression pattern of GFP was measured by flow cytometry and referred as measure of viral reactivation.

Results and discussion: The combination treatment of the dendrimers with the protein kinase C (PKC) agonist did not modify the antilatency activity in J89GFP lymphocyte cell line. Interestingly enough, G3-S16 dendrimer alone and its combination with BRY, RMD or PNB showed a significant increased expression of GFP in the THP89GFP monocyte cell line.

Conclusion: We showed for the first time that nanoparticles, in this case, G3-S16 anionic carbosilan dendrimer may play an important role in new treatments against HIV-1 infection.

Keywords: Nanomedicine, Dendrimers, HIV-1 latency, Latency reversal agents

\footnotetext{
*Correspondence: mmunoz.hgugm@gmail.com;

mmunoz.hgugm@salud.madrid.org

1 Molecular Immunology Laboratory, Hospital General Universitario

Gregorio Marañón, Madrid, Spain

Full list of author information is available at the end of the article
} 


\section{Background}

Human immunodeficiency virus-1 infection can be treated effectively in the developed world, using new combinations of antiretroviral treatments (cARTs). Despite prolonged cARTs, the persistence of HIV-1 in resting $\mathrm{CD}^{+} \mathrm{T}$ cells reservoirs harbouring transcriptional silence and replication-competent proviruses presents the major hurdle to HIV-1 eradication. These latently-infected cells are a permanent source for virus reactivation and lead to a rebound of the viral load after interruption of cARTs [1,2].

Various therapeutic interventions to eradicate HIV-1 focus on the stimulation of HIV-1 production from latently infected cells. These interventions involve the use of latency-reversing agents (LRAs) such as prostratin (PST), bryostatin-1,2 (BRY), panobinostat (PNB), and romidepsin (RMD) [3-9]. LRAs reactivate latentlyinfected cells, whereas the cARTs prevent spreading HIV-1 infection. It has been published that BRY, PNB and RMD present a good reactivation activity both in vitro and ex vivo and have currently been used in HIV-1 eradication clinical trials [10-12]. However, a decrease of the viral reservoir or total eradication of HIV-1 in infected subjects has not been achieved.

There are two major problems in HIV-1 infection: (1) virus persistence in reservoirs in a latent form integrated into the host genome, and virus replication when cells undergo activation; (2) inhibition of current ARV drugs with retrotranscription or with HIV-1 protease. This strategy presents additional troublesome such as the appearance of resistance. Drugs that interfere with ARV entry such as enfurtivide, which inhibits viral and cell membrane fusion, have been postulated as a possible alternative. However, the first cases of resistance have already been described [13].

In the last decade, the nanotechnology has been improved by the development and discovery of a wide range of novel nanoparticles. These new nanotechnology applications are easy to design, develop and synthesize. Dendrimers are promising nanoparticles, described as highly branched tree-like molecules between 1 and $40 \mathrm{~nm}$ [14]. We work with G1-S4, G2-S16 and G3-S16 polyanionic carbosilane dendrimers in the context of the HIV-1 infection $[15,16]$.

Our objective is to study the potential use of our polyanionic carbosilane dendrimers that will be applied in the "shock and kill" therapy increasing the HIV-1 reactivation and avoiding new HIV-1 infections.

\section{Materials and methods \\ Dendrimers}

Polyanionic carbosilane dendrimers G1-S4 with 4 sulfate groups in periphery, G2-S16 with 16 sulfonate groups in the periphery, and G3-S16 with 16 sulfate groups in the periphery were synthesized and analyzed according to methods reported by the Dendrimers for Biomedical Applications Group of University of Alcalá (Madrid, Spain) $[15,16]$. Stock solution of dendrimers $(10 \mathrm{mM})$ and subsequent dilutions to working concentrations were prepared in nuclease-free water (Promega, Madrid, Spain). The schematic structures of the polyanionic carbosilane dendrimers are presented in Fig. 1.

\section{Zeta potential}

These measurements were done in a Zetasizer Nano ZS (Malvern Instruments Ltd., UK) at $25{ }^{\circ} \mathrm{C}$ using disposable Malvern plastic cuvettes $(1 \mathrm{ml})$, by solving $1 \mathrm{mg}$ of dendrimers G1-S4, G2-S16 and G3-S16 in purified water, which was previously filtered through $0.22 \mu \mathrm{m}$ filter.

\section{Cell lines}

J89GFP lymphocyte and THP89GFP monocyte cell lines (kindly donated by Dr. David N Levy, NYU, USA), are derived cell lines latently infected with recombinant

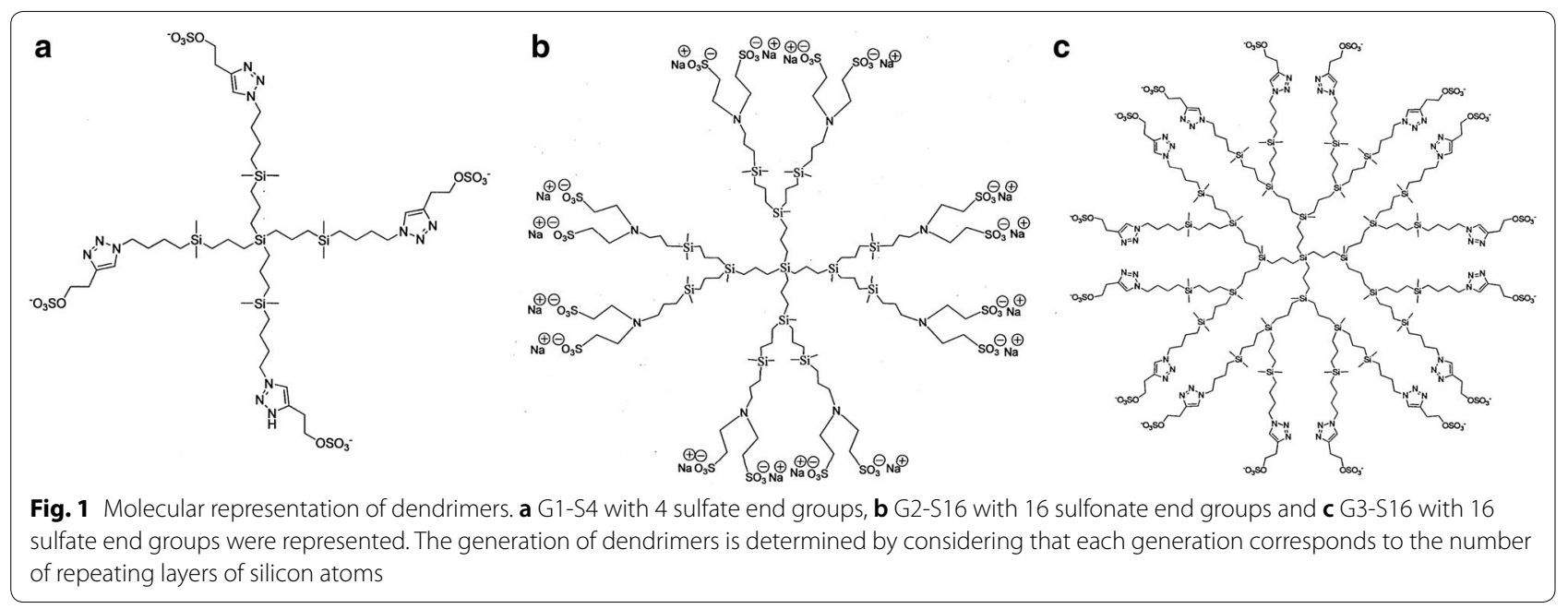


HIV-1 p89 GFP. J89GFP cell line was maintained in RPMI complemented with 5\% FBS, $125 \mathrm{mg} / \mathrm{ml}$ ampicillin, $125 \mathrm{mg} / \mathrm{ml}$ cloxacillin and $40 \mathrm{mg} / \mathrm{ml}$ gentamicin (Normon, Madrid, Spain). THP89GFP cell line was maintained in ultra-low attachment culture plates in DMEM complemented with $5 \%$ FBS, $125 \mathrm{mg} / \mathrm{ml}$ ampicillin, $125 \mathrm{mg} / \mathrm{ml}$ cloxacillin and $40 \mathrm{mg} / \mathrm{ml}$ gentamicin (Normon, Madrid, Spain) and were maintained according to the protocol described by Kutsch et al. [17].

\section{Reagents}

Bryostatin-1,2 (BRY) and prostratin (PST) were obtained from Sigma-Aldrich (St. Louis, MO, USA), panobinostat (PNB) and romidepsin (RMD) were obtained from Selleck Chemicals (Houston, TX). Drugs were dissolved in dimethyl sulfoxide (DMSO) (Sigma-Aldrich, St. Louis, MO, USA) to prepare stock solutions. DMSO concentration in cell cultures was lower than $0.001 \%$.

\section{Mitochondrial activity assay}

The mitochondrial toxicity of compound concentrations was tested by the 3-(4-5-dimethylthiazol-2-yl)-2,5-diphenyltetrazolium bromide (MTT) assay (Sigma, St Louis, USA) according to manufacturer's instructions in G1-S4, G2-S16 and G3-S16 dendrimers for 24 and $48 \mathrm{~h}$ and BRY, PST, PNB or RMD for $24 \mathrm{~h}$. Briefly, $6 \times 10^{4}$ of J89GFP or $2.5 \times 10^{4}$ THP89GFP cells were seeded in 96-well plates and treated with the desired compound for 24 or $48 \mathrm{~h}$. After incubation period, culture medium was discarded and $220 \mu \mathrm{l}$ of a 1:11 MTT/OptiMEM solution was added to the cultured cells. After $3 \mathrm{~h}$, the supernatant was removed, and formazan crystals were dissolved in $200 \mu \mathrm{l}$ DMSO (Sigma, St. Louis, MO, USA). All points were performed in triplicate. DMSO 10\% was used as death cellular control. The concentration range of each compound examined in this study is in agreement with previously published results $[18,19]$.

\section{Membrane integrity assay}

Cell membrane integrity was measured by the lactate deshidrogenase (LDH) assay CytoTox $96^{\circledR}$ Non-Radioactive Cytotoxicity (Promega, Spain, Madrid) following manufacturer's instructions. Briefly, $3 \times 10^{4}$ cells were seeded in 96-well plates and treated with the desired compounds and their combinations for $24 \mathrm{~h}$ and $48 \mathrm{~h}$. After incubation period, cells were lysed in $0.9 \%$ Triton X-100 (Promega, Spain, Madrid) for $45 \mathrm{~min}$ at $37{ }^{\circ} \mathrm{C}$. After incubation, $50 \mu \mathrm{l}$ of LDH reagent (Promega, Spain, Madrid) was added for $30 \mathrm{~min}$ at room temperature, protected from light absorbance was read in a Berthold
Plate Reader at $490 \mathrm{~nm}$. All points were performed by triplicate.

\section{Confocal microscopy}

GFP expression and LIVE/DEAD cells were analysed by confocal microscopy. J89GFP and THP89GFP were seeded at a density of $3 \times 10^{5}$ in 24 -well culture plates and ultra-low attachment plates, respectively. Subsequently, J89GFP and THP89GFP were treated with BRY, G2-S16 or G3-S16 for $48 \mathrm{~h}$ at $37{ }^{\circ} \mathrm{C}$. After incubation, both cell lines were treated with NUCLEAR-ID ${ }^{\circledR}$ Blue/Red cell viability reagent (ENZO, Farmingdale, New York) following manufacturer's instructions and visualized in a Leica TSC SPE confocal microscope. All points were performed in duplicate. DMSO 10\% was used as death cellular control.

\section{Latent HIV reactivation}

GFP-fluorescence pattern measured by flow cytometry was used to determine viral reactivation in J89GFP and THP89GFP cell lines. J89GFP and THP89GFP cells were seeded at a density of $4 \times 10^{5}$ in 24 -well culture plates and ultra-low attachment 24-well culture plates respectively, and after were stimulated with the indicated compounds. At least 30,000 cells were analysed by flow cytometry. The integrated mean fluorescence intensity (iMFI, percentage of GFP expressing cells "MFI) of live cells was used as a measure of HIV-1 reactivation.

\section{Statistics}

Statistical analysis was performed using GraphPad software Prism v.5.0 (GraphPad Software, San Diego, CA USA) between two groups (control versus different dosages of compounds or LRA-treated versus combined LRAs and G1-S4, G2-S16 or G3-S16) were assessed by using a paired t-test. (" $p<0.05$; ${ }^{* *} p<0.005$; $\left.{ }^{* * *} p<0.001\right)$.

\section{Results and discussion \\ Biocompatibility of latency reversing agents and dendrimers}

We previously described the potent activity of G1-S4, G2-S16 and G3-S16 dendrimers against HIV-1 infection [20-22]. Cell viability of sulfonate G2-S16 or sulfate G1-S4 and G3-S16 dendrimers, of nanoscale between 1 and $20 \mathrm{~nm}$ diameter, versatility and multi branching properties were studied on J89GFP lymphocyte and THP89GFP monocyte cell lines by MTT assay. Moreover, we studied by MTT and LDH assays the viability of BRY, PNB, PST and RMD in J89GFP and THP89GFP cell lines. The combinations of LRAs and dendrimers were analyzed by $\mathrm{LDH}$. 
J89GFP and THP89GFP cell lines were seeded and treated with G1-S4, G2-S16 or G3-S16 dendrimer in various range of concentrations to determine the maximum non-toxic concentration (Fig. 2). Dendrimers were considered non-toxic when the survival rate was $>80 \%$. Nontreated (NT) cells were used as cell viability control and DMSO 10\% was used as death cellular control for MTT assays.

The results of MTT showed that G1-S4 dendrimer was not toxic at $50 \mu \mathrm{M}$ and G2-S16 at $20 \mu \mathrm{M}$ in J89GFP cell line and both dendrimers were non-toxic at $50 \mu \mathrm{M}$ in THP89GFP cell lines during $24 \mathrm{~h}$ treatment. G1-S4 and G2-S16 dendrimers did not produce toxicity up to $20 \mu \mathrm{M}$ in THP89GFP and $10 \mu \mathrm{M}$ in J89GFP after $48 \mathrm{~h}$. However, G3-S16 maximum non-toxic concentration was only $1 \mu \mathrm{M}$ in both cell lines. G3-S16 was the dendrimer with the highest toxicity rates due to its major generation and bigger size. G2-S16 dendrimer with sulfonate groups in the surface was less toxic than G1-S4 with sulfate groups in J89GFP cell line after $48 \mathrm{~h}$ treatments, showing that not only the generation and size of the dendrimers, but also the functionalizing molecules are determinants for the biocompatibility.

The selection of the LRA concentrations was performed taking into account the maximum non-toxic concentration for each drug previously reported [23, 24].
BRY was non-toxic up to $100 \mathrm{nM}$, PST up to $20 \mu \mathrm{M}$, PNB up to $40 \mathrm{nM}$, and RMD showed toxicity at $20 \mathrm{nM}$ (Fig. 3).

Combinations of dendrimers with LRAs in the J89GFP cell line showed no toxicity at $24 \mathrm{~h}$. The viability decreased below $80 \%$ for PST, RMD and PNB after $48 \mathrm{~h}$ treatment analysed by LDH assay. Results indicated that after $48 \mathrm{~h}$ dendrimers did not produce cytotoxicity. However, combinations with LRAs reduced viability, probably due to the basal toxicity of LRAs on this cell line (Fig. 4).

In THP89GFP cell line, LRAs treatment for $24 \mathrm{~h}$ did not produce a decrease in the cell viability. Similarly, the dendrimers alone or in combination with BRY and PST did not produce toxicity. On the other hand, combination of G1-S4 and G3-S16 with RMD and PNB caused a 20\% decrease in viability. No cell toxicity was observed at $48 \mathrm{~h}$ following single treatment with either BRY, PST or dendrimers single treatment. However, RMD, PNB and their combinations with dendrimers reduced viability below 80\% in THP89GFP cells.

Exposure of J89GFP or THP89GFP cells to either G2-S16 (up to $10 \mu \mathrm{M}$ ) or G3-S16 (up to $1 \mu \mathrm{M}$ ) did not show toxicity following 24 and $48 \mathrm{~h}$ of treatment. However, G1-S4 reduced J89GFP cells viability measured by MTT at $48 \mathrm{~h}$.

Potential z measurements were performed to study the aggregation ratio in aqueous solution. Due to technical
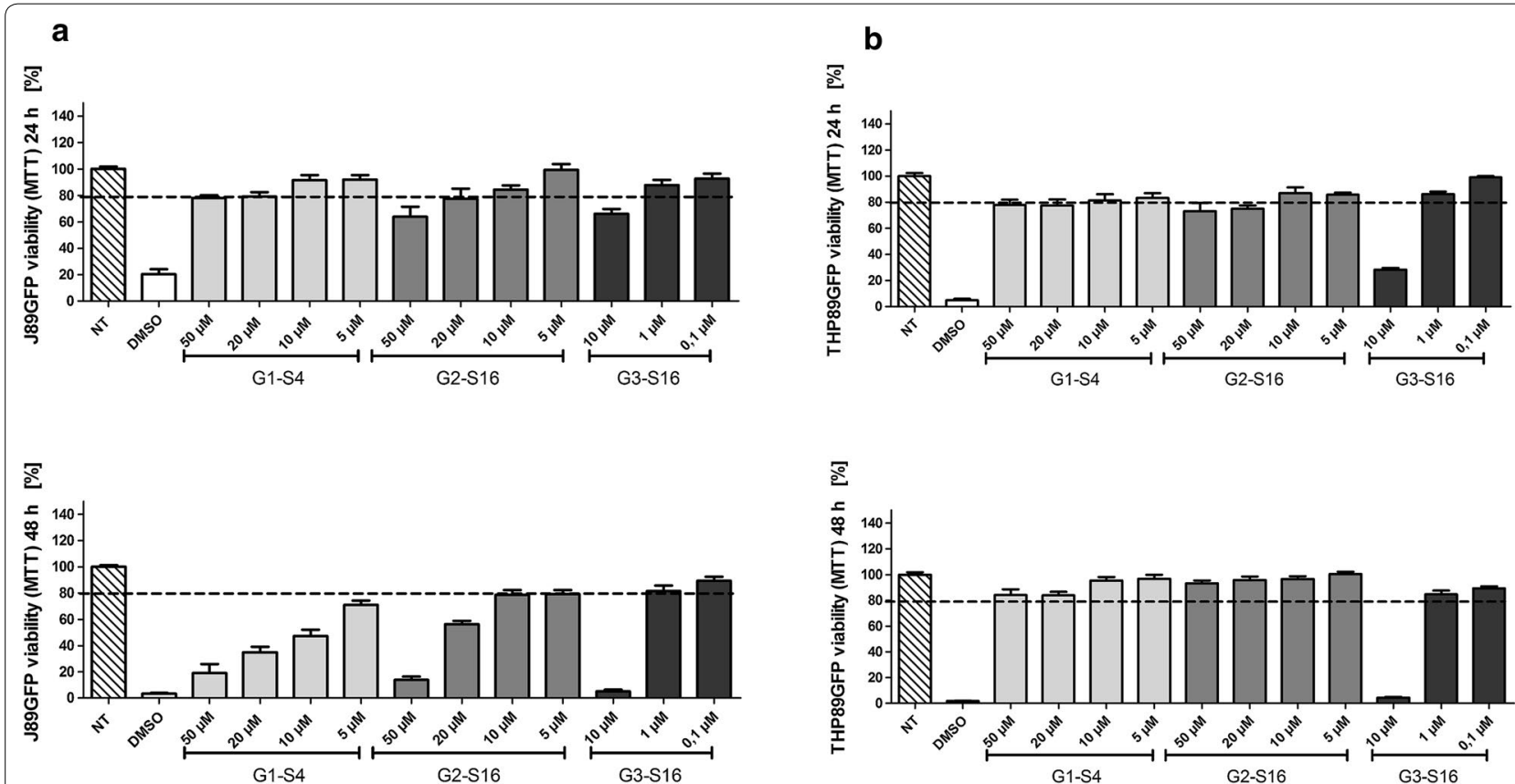

Fig. 2 Mitochondrial activity studies of polyanionic carbosilane dendrimers. MTT assays were performed in a J89GFP lymphocyte and b THP89GFP monocyte cell lines for $24 \mathrm{~h}$ and $48 \mathrm{~h}$. Cell lines were treated with increased concentration range (0.2-50 $\mu \mathrm{M}$ ) of G1-S4, G2-S16 or G3-S16 dendrimers. Non-treated (NT) cells were used as cell viability control. DMSO was used as cell death control. NT non-treated control, DMSO dimethyl sulfoxide. The mean values (mean \pm SD) of two or three independent experiments are shown $\left({ }^{*} p<0.05 ;{ }^{* *} p<0.005 ;{ }^{* * *} p<0.001\right.$ ) 

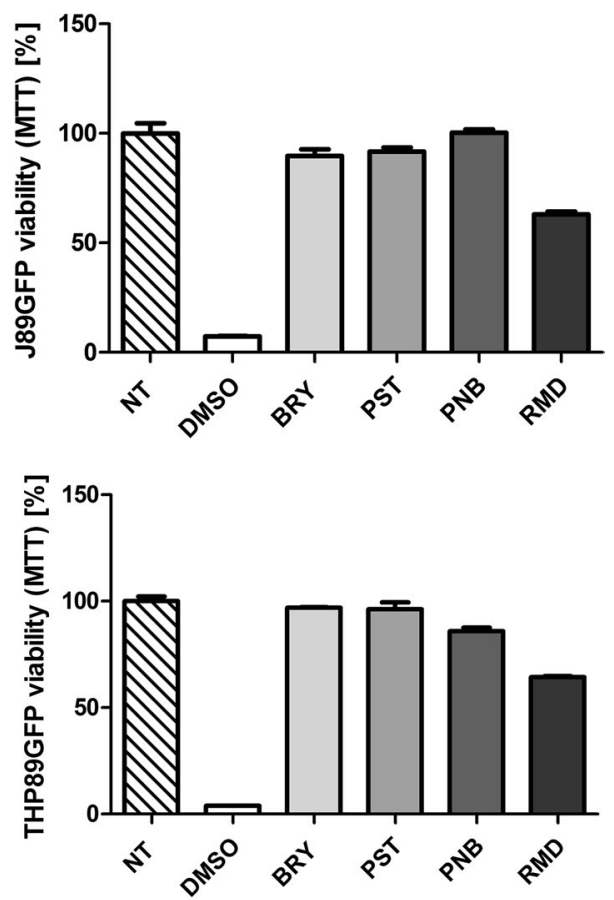

Fig. 3 Mitochondrial activity studies of latency reversal agents. MTT assays were performed on J89GFP lymphocyte and THP89GFP monocyte cell lines during $24 \mathrm{~h}$. Both cell lines were treated with BRY up to $100 \mathrm{nM}$, PST up to $20 \mu \mathrm{M}$, PNB up to $40 \mathrm{nM}$, and RMD up to $20 \mathrm{nM}$. Non-treated (NT) cells were used as cell viability control. DMSO was used as cell death control. NT non-treated control, DMSO dimethyl sulfoxide. The mean values (mean $\pm \mathrm{SD}$ ) of three independent experiments are shown $\left({ }^{*} p<0.05\right.$; ${ }^{* *} p<0.005$; $\left.{ }^{* * *} p<0.001\right)$

issues with the small size of G1-S4, potential $\mathrm{z}$ for this dendrimer was not available. On the other hand, G2-S16 dendrimer z potential was $-74.0 \mathrm{mV}$ showing high longterm stability in aqueous solutions which demonstrate a good biocompatibility in cell culture. G3-S16 showed a higher $\mathrm{z}$ potential, $-46.2 \mathrm{mV}$. These results agree with the viability data obtained by MTT and LDH assays, indicating that just $1 \mu \mathrm{M}$ was the maximum non-toxic concentration for G3-S16, while for G2-S16 was ten times higher, $10 \mu \mathrm{M}$.

Reactivation was measured by determining GFP expression in living cells. Confocal microscope images of non-treated, G2-S16, G3-S16, BRY and DMSO 10\% were taken to confirm the expression of GFP in live cells (Fig. 5). Results of NT and DMSO 10\% in both cell lines represented viability and death control, showed in blue and red respectively. BRY was used as reactivation control, represented in green. In J89GFP cell line results showed that only BRY treatment leads to HIV-1 reactivation. However, in THP89GFP cell line, results indicate that G3-S16 dendrimer promotes GFP expression.
Reactivation profile of LRAs in combinations with dendrimers in latently HIV-1 infected cell lines

Our dendrimers are directed for a possible therapeutic treatment. In this context we have previously shown that these dendrimers inhibit HIV-1 infection and can be used in combination with different antiretrovirals [25-27]. However, we do not know what function the dendrimers have in the presence of LRAs. Therefore, we studied their potential effect in the presence of LRAs. To determine the viral reactivation, the GFP-fluorescence pattern was measured by flow cytometry.

The HIV-1 reactivation effect of BRY, PST, PNB and RMD were analysed as individual drugs or in combination with G1-S4, G2-S16 or G3-S16 dendrimers at various ratios. The concentrations of the dendrimers were based on the non-toxic concentration $10 \mu \mathrm{M}$ G1-S4, $10 \mu \mathrm{M}$ G2-S16 and $1 \mu \mathrm{M}$ G3-S16 previously selected. The selection of LRA concentrations were performed, taking into account the maximum non-toxic concentration of each LRA based on the scientific literature, $100 \mathrm{nM}$ BRY, $20 \mu \mathrm{M}$ PST, $40 \mathrm{nM}$ PNB, and $20 \mathrm{nM}$ RMD. After $24 \mathrm{~h}$ and $48 \mathrm{~h}$ of exposure, the reactivation effect was measured by flow cytometry and expressed as GFP (integrated MFI or iMFI) (Fig. 6).

Our results indicate the enhanced GFP expression with the treatment of the LRAs alone in J89GFP cell line at $24 \mathrm{~h}$ of exposure. The PST induced the highest response at $55 \%$ of EGFP expression. In the case of the dendrimers alone, the GFP expression was not modified in regards of the non-treated control. The combination treatment of LRAs and dendrimers indicate that the antilatency activity of the LRAs was not modified, even in some cases it tends to increase slightly in combination with G1-S4, G2-S16 or G3-S16 dendrimers. At $48 \mathrm{~h}$ BRY, PST, RMD or PNB tend to increase the GFP expression in J89GFP cell line. Nevertheless, RMD in combination with G1-S4 showed an increased tendency in the expression of GFP. Neither of the three dendrimers studied alone show any variation in the GFP expression in the lymphocytic derived cell line. The combination of either G1-S4, G2-S16 or G3-S16 with BRY and PST in J89GFP lymphocytic cell line at $48 \mathrm{~h}$ did not modify the GFP expression. Our data indicate that the combination treatment of our dendrimers with the PKC agonist did not modify the antilatency activity.

In the THP89GFP, monocytic derived cell line, we obtained different results. The GFP expression in the single LRAs treatment at $24 \mathrm{~h}$ was greatly increased in comparison with the J89GFP lymphocytic cell line, reaching $80 \%$ of GFP expression with BRY. The LRAs combination with G1-S4 or G2-S16 dendrimer did not show any variation of the GFP expression in regards of treatment of LRAs alone. Surprisingly, in THP89GFP monocytic 

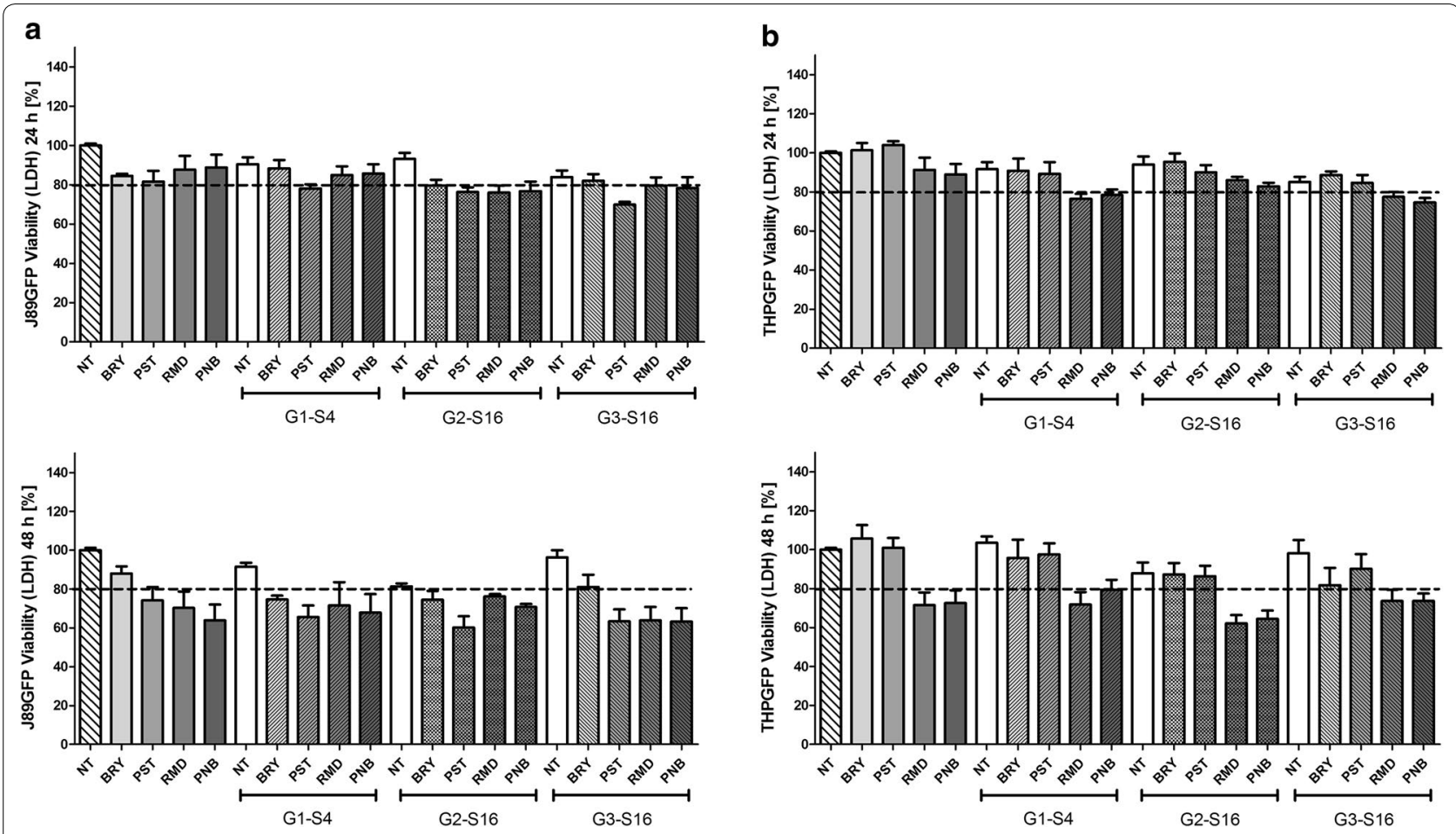

Fig. 4 Membrane integrity studies of carbosilane dendrimers and LRAs combinations. LDH assays were performed on a J89GFP lymphocyte and

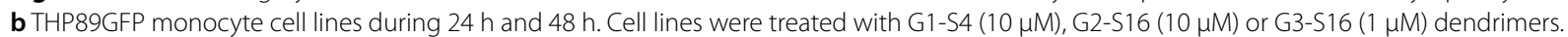
Both cell lines were treated with BRY $(100 \mathrm{nM})$, PST $(20 \mu \mathrm{M})$, PNB $(40 \mathrm{nM})$ or RMD $(20 \mathrm{nM})$. Non-treated (NT) cells were used as cell viability control. NT non-treated control, BRY bryostatin, PST prostratin, RMD romidepsin, PNB panobinostat. The mean values (mean \pm SD) of three independent experiments are shown $\left({ }^{*} p<0.05 ;{ }^{* *} p<0.005 ;{ }^{* * *} p<0.001\right.$ )

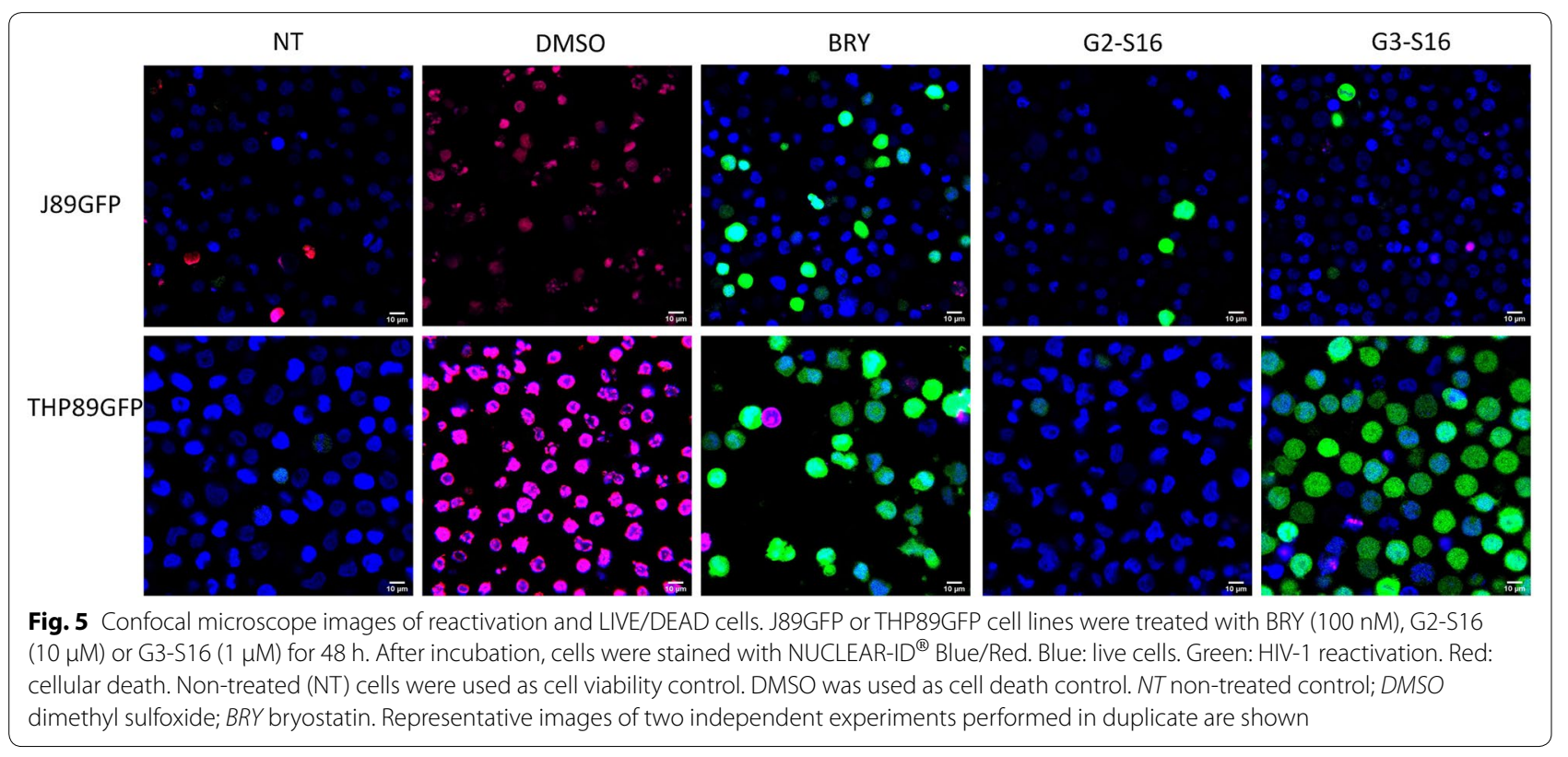



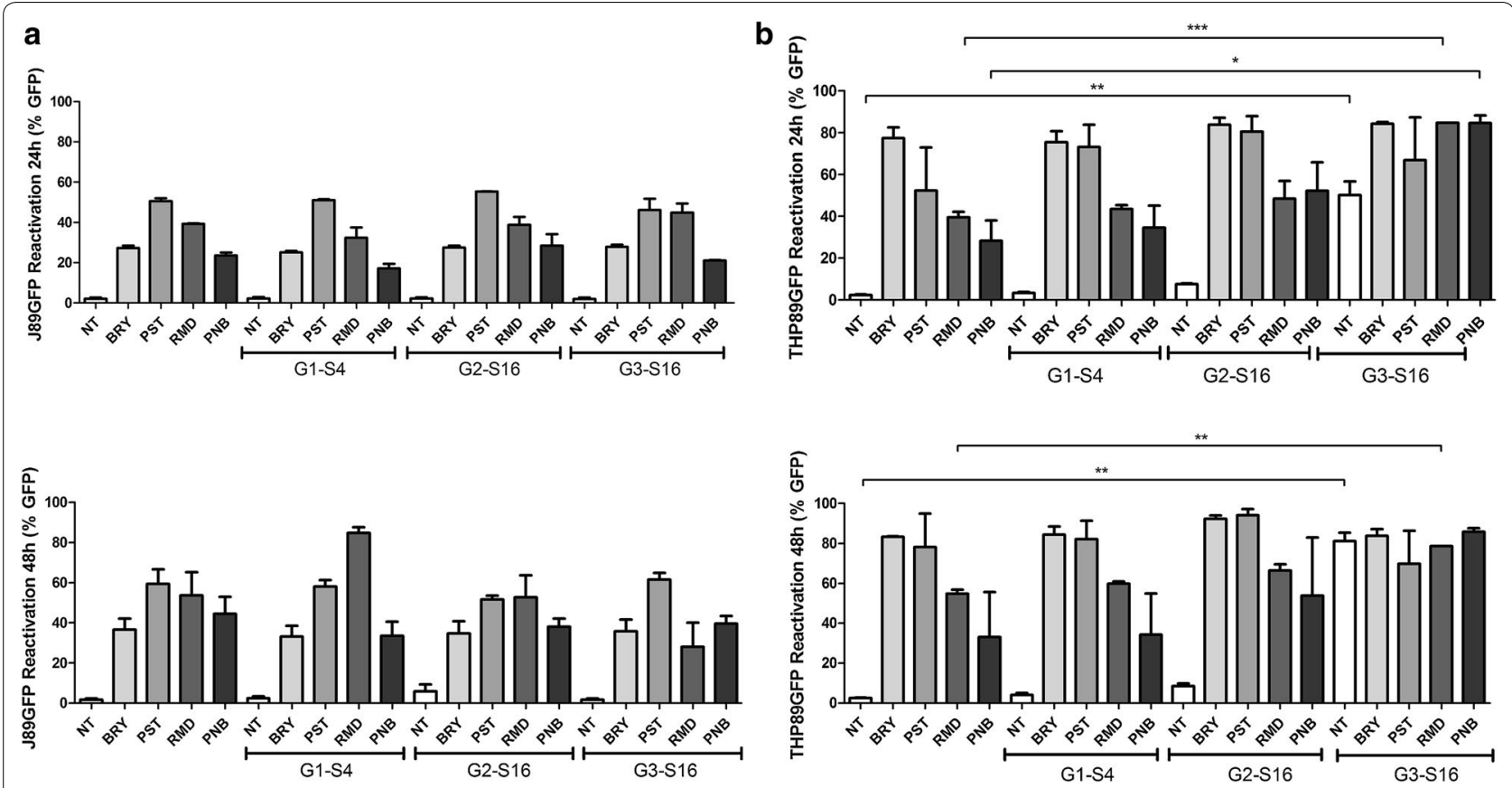

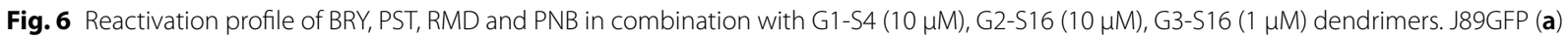
and THP89GFP $(\mathbf{b})$ cell lines were treated with BRY $(100 \mathrm{nM})$, PST $(20 \mu \mathrm{M}), \mathrm{RMD}(20 \mathrm{nM})$ and PNB $(40 \mathrm{~nm})$, either alone or in combinations with dendrimers for $24 \mathrm{~h}$ and $48 \mathrm{~h}$. The integrated mean fluorescence intensity (iMFI, percentage of GFP expressing cells *MFI) of live cells was used as a measure of HIV-1 reactivation. NT non-treated control, BRY bryostatin, PST prostratin, RMD romidepsin; PNB panobinostat. The mean values $(m e a n \pm S D)$ of two or three independent experiments are shown $\left({ }^{*} p<0.05 ;{ }^{* *} p<0.005 ;{ }^{* * *} p<0.001\right)$

cell line, the G3-S16 dendrimer alone treatment showed a significant increased expression of GFP reaching $50 \%$. We hypothesize that high size of G3-S16 in addition to sulfate groups in its periphery activate the monocytes, thus unleashing transcription factors such as NF-Kb or Sp1, forcing the viral reactivation and transcription [28]. In the case of the combinations of LRAs with G3-S16, the results showed an enhanced expression of GFP reaching almost $80 \%$ for BRY, RMD and PNB. This result proves a new possible approach for a combination treatment in the "shock and kill" method with dendrimers, which not only inhibit the entry of new replicative viruses, but also help with the reactivation activity of LRAs. Although our results are promising, the mechanism of our dendrimers reactivation and the use of more physiological models such as latently infected primary cells or in vivo models should be studied. Summing up, we demonstrated for the first time that nanoparticles, in this case dendrimers may play an important role in new treatments against HIV-1 infection.

\section{Authors' contributions}

MAMF designed the study, developed the methodology, analysed and discussed data and wrote the manuscript. EM designed the study, analysed and discussed data. IR and RJ performed experiments, analyzed the data, composed the figures, interpreted and discussed the data. CP analyzed the data, interpreted and discussed the data. All authors read and approved the final manuscript.

\section{Funding}

This work has been (partially) funded by the RD16/0025/0019, project as part of the project Acción Estratégica en Salud, Plan Nacional de Investigación Científica, Desarrollo e Innovación Tecnológica (2013-2016) and co-financed by the Instituto de Salud Carlos III (Subdirección General de Evaluación) and Fondo Europeo de Desarrollo Regional (FEDER), RETIC PT17/0015/0042, Fondo de Investigacion Sanitaria (FIS) (Grant Number PI16/01863), EPIICAL Project. CIBER-BBN is an initiative funded by the VI National R\&D\&I Plan 2008-2011, Iniciativa Ingenio 2010, the Consolider Program, and CIBER Actions and financed by the Instituto de Salud Carlos III with assistance from the European Regional Development Fund. COST CA17140 Cancer Nanomedicine-Front The Bench to Bebside.

\section{Availability of data and materials}

The datasets used and/or analysed during the current study are available from the corresponding author on reasonable request.

\section{Ethics approval and consent to participate}

Not applicable.

\section{Consent for publication \\ Not applicable.}

\section{Competing interests}

The authors declare that they have no competing interests.

\section{Author details}

${ }^{1}$ Molecular Immunology Laboratory, Hospital General Universitario Gregorio Marañón, Madrid, Spain. ${ }^{2}$ Health Research Institute Gregorio Marañón (liSGM), 
Spanish HIV HGM BioBank, Madrid, Spain. ${ }^{3}$ Networking Research Center on Bioengineering, Biomaterials and Nanomedicine (CIBER-BBN), Madrid, Spain. ${ }^{4}$ Innohealth, Parque Científico de Madrid, Madrid, Spain. ${ }^{5}$ Department of Cell Biology, Physiology and Immunology, Instituto Maimónides de Investigaciones Biomédicas de Córdoba (IMIBIC)/Reina Sofia University Hospital University of Córdoba, Córdoba, Spain.

Received: 13 November 2018 Accepted: 7 May 2019

Published online: 21 May 2019

\section{References}

1. Gutierrez C, Diaz L, Vallejo A, Hernandez-Novoa B, Abad M, Madrid N, et al Intensification of antiretroviral therapy with a CCR1 antagonist in patients with chronic HIV-1 infection: effect on T cells latently infected. PLOS ONE. 2011;6(12):e27864.

2. Gutierrez C, Hernandez-Novoa B, Vallejo A, Serrano-Villar S, AbadFernandez M, Madrid N, et al. Dynamics of the HIV-1 latent reservoir after discontinuation of the intensification of antiretroviral treatment: results of two clinical trials. AIDS. 2013;27(13):2081-8.

3. Archin NM, Liberty AL, Kashuba AD, Choudhary SK, Kuruc JD, Crooks AM, et al. Administration of vorinostat disrupts HIV-1 latency in patients on antiretroviral therapy. Nature. 2012:487(7408):482-5.

4. del Real G, Jimenez-Baranda S, Mira E, Lacalle RA, Lucas P, Gomez-Mouton C, et al. Statins inhibit HIV-1 infection by down-regulating Rho activity. J Exp Med. 2004;200(4):541-7.

5. Furumai R, Matsuyama A, Kobashi N, Lee KH, Nishiyama M, Nakajima $\mathrm{H}$, et al. FK228 (depsipeptide) as a natural prodrug that inhibits class I histone deacetylases. Cancer Res. 2002;62(17):4916-21.

6. Kulkosky J, Bray S. HAART-persistent HIV-1 latent reservoirs: their origin, mechanisms of stability and potential strategies for eradication. Curr HIV Res. 2006;4(2):199-208.

7. Kulkosky J, Culnan DM, Roman J, Dornadula G, Schnell M, Boyd MR, et al. Prostratin: activation of latent HIV-1 expression suggests a potential inductive adjuvant therapy for HAART. Blood. 2001;98(10):3006-15.

8. Mehla R, Bivalkar-Mehla S, Zhang R, Handy I, Albrecht H, Giri S, et al. Bryostatin modulates latent HIV-1 infection via PKC and AMPK signaling but inhibits acute infection in a receptor independent manner. PLOS ONE. 2010;5(6):e11160

9. Rasmussen TA, Tolstrup M, Winckelmann A, Ostergaard L, Sogaard OS. Eliminating the latent HIV reservoir by reactivation strategies: advancing to clinical trials. Hum Vaccines Immunother. 2013;9(4):790-9.

10. Zonder JA, Shields AF, Zalupski M, Chaplen R, Heilbrun LK, Arlauskas P, et al. A phase II trial of bryostatin 1 in the treatment of metastatic colorectal cancer. Clin Cancer Res. 2001;7(1):38-42.

11. Wei DG, Chiang V, Fyne E, Balakrishnan M, Barnes T, Graupe M, et al. Histone deacetylase inhibitor romidepsin induces HIV expression in CD4 T cells from patients on suppressive antiretroviral therapy at concentrations achieved by clinical dosing. PLoS Pathog. 2014;10(4):e1004071.

12. Van Lint C, Bouchat $S$, Marcello A. HIV-1 transcription and latency: an update. Retrovirology. 2013;10:67.

13. Reis MN, de Alcantara KC, Cardoso LP, Stefani MM. Polymorphisms in the HIV-1 gp41 env gene, natural resistance to enfuvirtide (T-20) and pol resistance among pregnant Brazilian women. J Med Virol. 2014;86(1):8-17.

14. Vacas-Cordoba E, Maly M, De la Mata FJ, Gomez R, Pion M, Munoz-Fernandez MA. Antiviral mechanism of polyanionic carbosilane dendrimers against HIV-1. Int J Nanomed. 2016;11:1281-94.

15. Rasines B, Sanchez-Nieves J, Maiolo M, Maly M, Chonco L, Jimenez JL, et al. Synthesis, structure and molecular modelling of anionic carbosilane dendrimers. Dalton Trans. 2012;41(41):12733-48.
16. Arnáiz E, Vacas-Cordoba E, Galan M, Pion M, Gomez R, Muñoz-Fernandez $M$, et al. Synthesis of anionic carbosilane dendrimers via "click chemistry" and their antiviral properties against HIV. J Polymer Sci. 2014;52:1055-215.

17. Kutsch O, Benveniste EN, Shaw GM, Levy DN. Direct and quantitative single-cell analysis of human immunodeficiency virus type 1 reactivation from latency. J Virol. 2002;76(17):8776-86.

18. Arberas H, Guardo AC, Bargallo ME, Maleno MJ, Calvo M, Blanco JL, et al. In vitro effects of the CCR17 inhibitor maraviroc on human $T$ cell function. J Antimicrob Chemother. 2013;68(3):577-86.

19. Bousquet L, Pruvost A, Guyot AC, Farinotti R, Mabondzo A. Combination of tenofovir and emtricitabine plus efavirenz: in vitro modulation of $A B C$ transporter and intracellular drug accumulation. Antimicrob Agents Chemother. 2009;53(3):896-902

20. Cena-Diez R, Garcia-Broncano P, Javier de la Mata F, Gomez R, Resino S, Munoz-Fernandez M. G2-S16 dendrimer as a candidate for a microbicide to prevent HIV-1 infection in women. Nanoscale. 2017;9(27):9732-42.

21. Garcia-Broncano P, Cena-Diez R, de la Mata FJ, Gomez R, Resino S, MunozFernandez MA. Efficacy of carbosilane dendrimers with an antiretroviral combination against HIV-1 in the presence of semen-derived enhancer of viral infection. Eur J Pharmacol. 2017;811:155-63.

22. Sepulveda-Crespo D, Serramia MJ, Tager AM, Vrbanac V, Gomez R, De La Mata FJ, et al. Prevention vaginally of HIV-1 transmission in humanized BLT mice and mode of antiviral action of polyanionic carbosilane dendrimer G2-S16. Nanomedicine. 2015;11(6):1299-308.

23. Martinez-Bonet M, Clemente MI, Alvarez S, Diaz L, Garcia-Alonso D, Munoz E, et al. Antiretroviral drugs do not interfere with bryostatin-mediated HIV-1 latency reversal. Antiviral Res. 2015;123:163-71.

24. Martinez-Bonet M, Clemente MI, Serramia MJ, Munoz E, Moreno S, Munoz-Fernandez MA. Synergistic activation of latent HIV-1 expression by novel histone deacetylase inhibitors and bryostatin-1. Sci Rep. 2015;5:16445.

25. Sepulveda-Crespo D, Sanchez-Rodriguez J, Serramia MJ, Gomez R, De La Mata FJ, Jimenez JL, et al. Triple combination of carbosilane dendrimers, tenofovir and maraviroc as potential microbicide to prevent HIV-1 sexual transmission. Nanomedicine. 2015;10(6):899-914.

26. Sepulveda-Crespo D, Lorente R, Leal M, Gomez R, De la Mata FJ, Jimenez $J$, et al. Synergistic activity profile of carbosilane dendrimer G2-STE16 in combination with other dendrimers and antiretrovirals as topical antiHIV-1 microbicide. Nanomedicine. 2014;10(3):609-18.

27. Cordoba EV, Arnaiz E, De La Mata FJ, Gomez R, Leal M, Pion M, et al. Synergistic activity of carbosilane dendrimers in combination with maraviroc against HIV in vitro. AIDS. 2013;27(13):2053-8.

28. Gonzalez OA, Li M, Ebersole JL, Huang CB. HIV-1 reactivation induced by the periodontal pathogens Fusobacterium nucleatum and Porphyromonas gingivalis involves Toll-like receptor 2 [corrected] and 9 activation in monocytes/macrophages. Clin Vaccine Immunol. 2010;17(9):1417-27.

\section{Publisher's Note}

Springer Nature remains neutral with regard to jurisdictional claims in published maps and institutional affiliations.

Ready to submit your research? Choose BMC and benefit from:

- fast, convenient online submission

- thorough peer review by experienced researchers in your field

- rapid publication on acceptance

- support for research data, including large and complex data types

- gold Open Access which fosters wider collaboration and increased citations

- maximum visibility for your research: over 100M website views per year

At BMC, research is always in progress.

Learn more biomedcentral.com/submissions 